\title{
Resource usage in outpatient care and reimbursement for cystic fibrosis in Germany
}

\begin{tabular}{|c|c|}
\hline Journal: & Pediatric Pulmonology \\
\hline Manuscript ID: & PPUL-09-0380.R2 \\
\hline Wiley - Manuscript type: & Original Article \\
\hline $\begin{array}{r}\text { Date Submitted by the } \\
\text { Author: }\end{array}$ & 15-May-2010 \\
\hline Complete List of Authors: & $\begin{array}{l}\text { Eidt-Koch, Daniela; University of Hannover, Centre for Health } \\
\text { Economics } \\
\text { Wagner, Thomas O. F.; CF-Adult Centre, Johann Wolfgang Goethe- } \\
\text { University } \\
\text { Mittendorf, Thomas; University of Hannover, Centre for Health } \\
\text { Economics } \\
\text { Reimann, Andreas; Mukoviszidose e.V. } \\
\text { Schulenburg, J.-Matthias; University of Hannover, Centre for Health } \\
\text { Economics }\end{array}$ \\
\hline Keywords: & Cost analysis, reimbursement, cystic fibrosis, Germany \\
\hline
\end{tabular}

\section{^scholarONE" \\ Manuscript Central}


Table 3: Correlations of costs for outpatient treatment

\begin{tabular}{|l|c|}
\hline Independent variable & Correlation coefficient (Spearman) \\
\hline Age group / age & $0.264 / 0.233(\mathrm{p}<0.010)^{*}$ \\
\hline Pancreatic insufficiency & $0.143(\mathrm{p}<0.050)^{* *}$ \\
\hline Hepatobiliary complications & $0.225(\mathrm{p}<0.010)^{*}$ \\
\hline Diabetes mellitus & $0.110(\mathrm{p}<0.050)^{* *}$ \\
\hline Nasal polyps & $0.111(\mathrm{p}<0.050)^{* *}$ \\
\hline Bacterial lung colonization with & $0.210(\mathrm{p}<0.010)^{*}$ \\
\hline$\%$ FEV1 & $-0.125(\mathrm{p}=0.053)$ \\
\hline
\end{tabular}

$*=$ significant with $\mathrm{p}<0.010$

$* *=$ significant with $\mathrm{p}<0.050$ 
Table 4: Cost analysis with regard to selected cost-influencing factors

\begin{tabular}{|l|c|}
\hline Cost-influencing factor & Average total costs \\
\hline Age group / age & \\
Children (0 to 17 years) & $466.66 €$ \\
Adults (18 years and older) & $509.16 €$ \\
\hline Pancreatic insufficiency (PI) & \\
Without PI & $454.08 €$ \\
With PI & $496.18 €$ \\
\hline Bacterial lung colonization (Col) & \\
Without Col & $451.03 €$ \\
With Col & $500.84 €$ \\
\hline$\%$ of FEV & \\
FEV $180 \%$ (standard values) & $497.19 €$ \\
$60 \% \leq \mathrm{FEV}<80 \%$ (low severity) & $531.73 €$ \\
$40 \% \leq \mathrm{FEV}$ < $60 \%$ (medium severity) & $499.23 €$ \\
$\mathrm{FEV}_{1}<40 \%$ (severe restrictions) & $538.09 €$ \\
\hline
\end{tabular}


Table 5: Calculation of a flat fee covering resource usage

\begin{tabular}{|l|c|c|}
\hline & $\begin{array}{c}\text { Children and adolescents } \\
\text { (0 to } 17 \text { years })\end{array}$ & $\begin{array}{c}\text { Adults } \\
\text { (18 years and older) }\end{array}$ \\
\hline $\begin{array}{l}\text { Average total costs } \\
\text { per age group }\end{array}$ & $466.66 €$ & $509.16 €$ \\
\hline $\begin{array}{l}\text { Average total costs without } \\
\text { pancreatic insufficiency } \\
\text { Average total costs with } \\
\text { pancreatic insufficiency }\end{array}$ & $440.20 €$ & $469.93 €$ \\
\hline $\begin{array}{l}\text { Average total costs without } \\
\text { bacterial lung colonization } \\
\text { Average total costs with } \\
\text { bacterial lung colonization }\end{array}$ & $473.33 €$ & $517.07 €$ \\
\hline
\end{tabular}


Table 6: Calculation of a „CF flat charge“ in addition to remuneration by German EBM figures

\begin{tabular}{|l|c|c|c|}
\hline & $\begin{array}{c}\text { Average total } \\
\text { costs }\end{array}$ & $\begin{array}{c}\text { Average EBM } \\
\text { reimbursement }\end{array}$ & $\begin{array}{c}\text { "CF flat charge“ } \\
\text { per patient and quarter }\end{array}$ \\
\hline $\begin{array}{l}\text { Children and adolescents } \\
\text { ( to } 17 \text { years })\end{array}$ & $466.66 €$ & $104.79 €$ & $361.87 €$ \\
$\begin{array}{l}\text { Adults } \\
(18 \text { years and older })\end{array}$ & $509.16 €$ & $148.88 €$ & $360.28 €$ \\
\hline
\end{tabular}




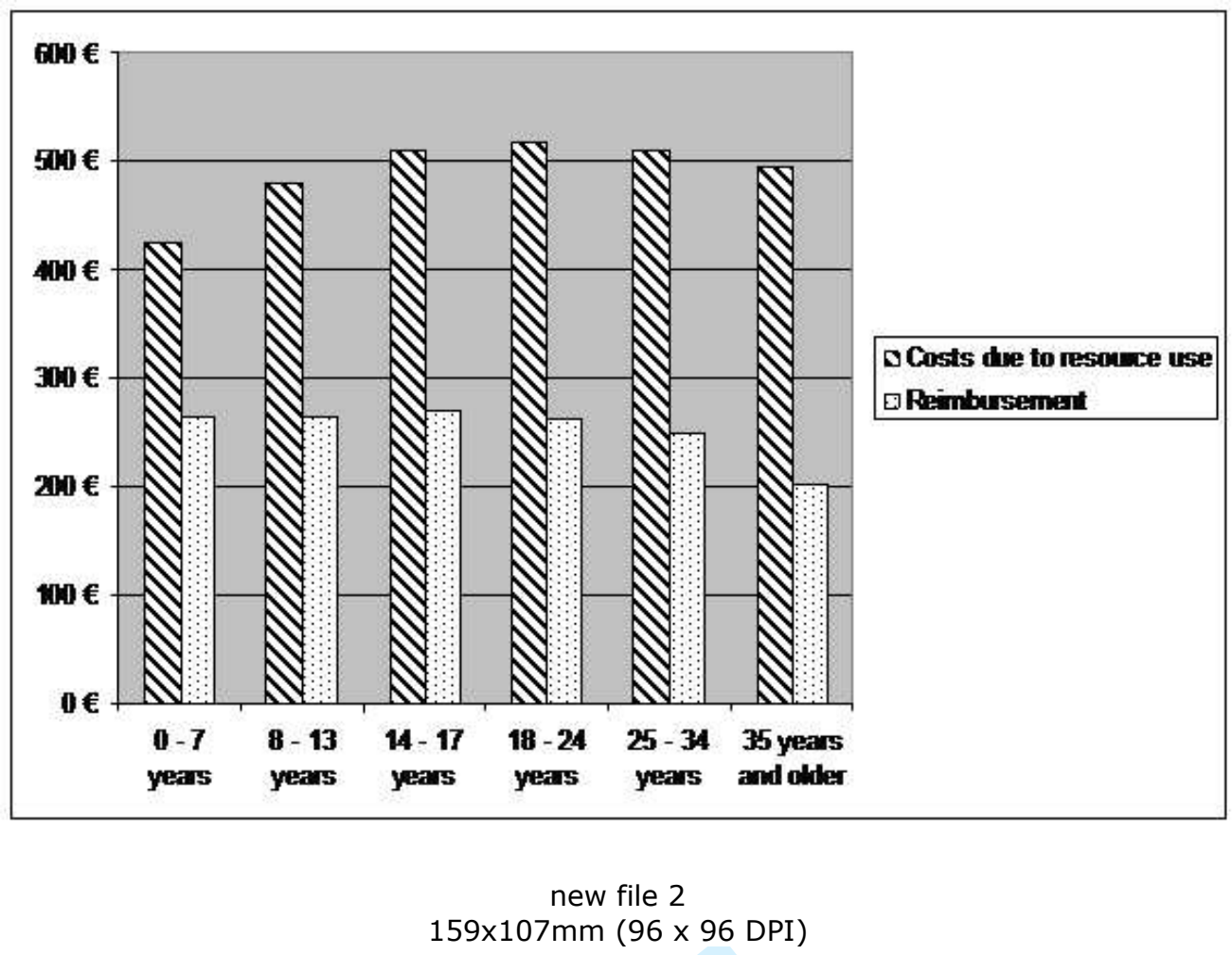

John Wiley \& Sons, Inc. 
Figure 1: Costs for outpatient care

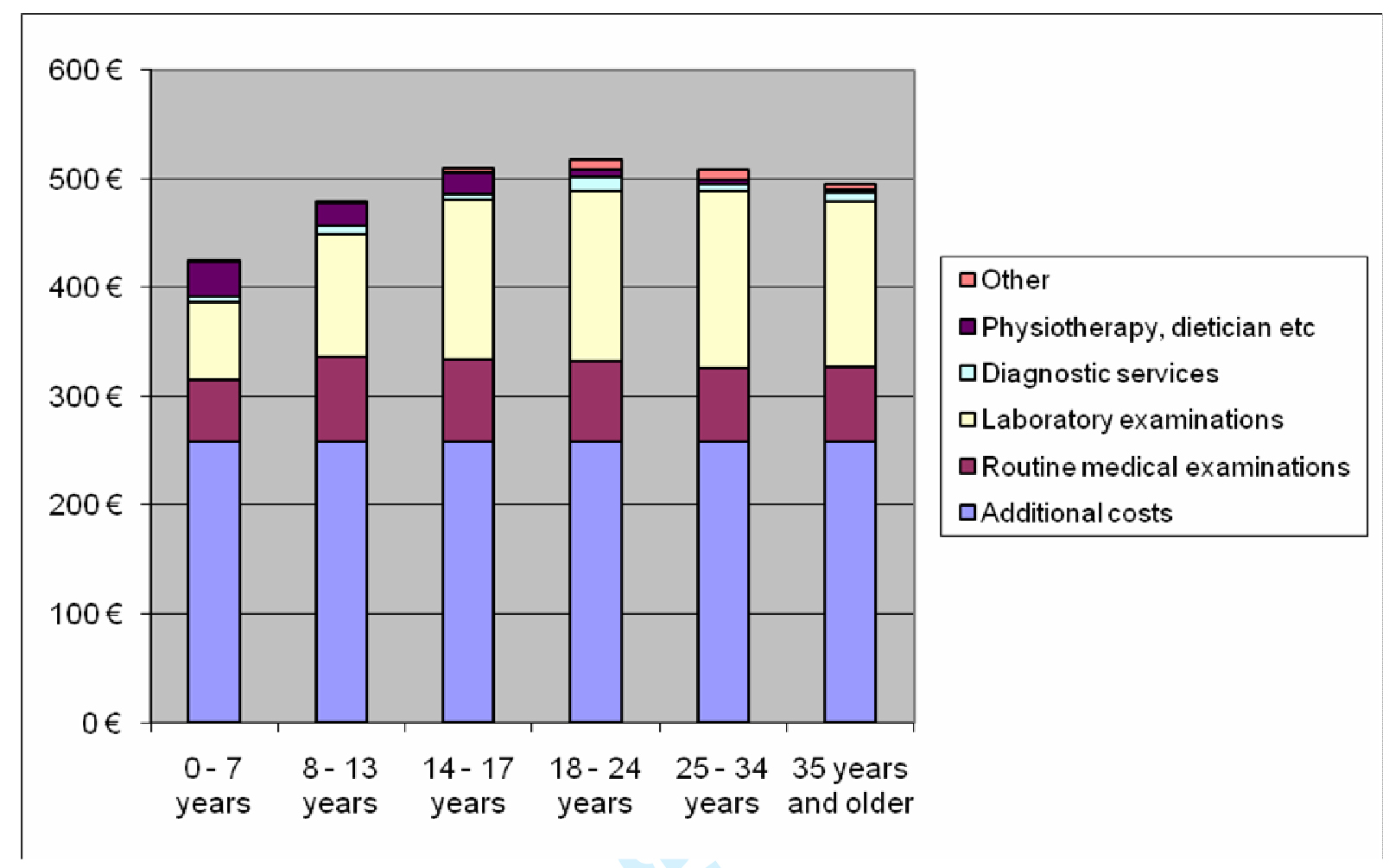




\title{
Original article
}

\section{Resource usage in outpatient care and reimbursement for cystic fibrosis in Germany}

\author{
Eidt-Koch, Daniela* PhD \\ Wagner, Thomas O.F. ** MD \\ Mittendorf, Thomas * PhD \\ Reimann, Andreas *** $\mathrm{PhD}$ \\ von der Schulenburg, J.-Matthias * PhD \\ * Centre for Health Economics, Leibniz University of Hannover, Germany \\ ** CF-Adult Centre, Johann Wolfgang Goethe-University, Frankfurt, Germany \\ *** Mukoviszidose e.V., Bonn, Germany
}

Key Words: Cost analysis, reimbursement, cystic fibrosis, Germany

Correspondence:

Dr. Daniela Eidt-Koch, Leibniz University Hannover, Centre for Health Economics,

Koenigsworther Platz 1; D-30167 Hannover, Email: de@ivbl.uni-hannover.de; Tel : +49-511$762-5518 ;$ Fax : +49-511-762-5081

Running title: Cost analysis for cystic fibrosis in Germany 


\section{Details of funding / Competing interests / Statement of independence of researchers from funders}

The study has been funded by Mukoviszidose e.V, the German CF association, Andreas Reimann is executive director and Thomas OF Wagner is board member of Mukoviszidose e.V. However, the research of the study is independent from this relationship as well as the funding.

\section{Acknowledgements}

We would like to thank Mukoviszidose e.V., the German Cystic Fibrosis Association, as well as the clinics and patients for their support and information they provided for this analysis. Especially we thank the CF Study Groups from the following clinics: Manfred Ballmann (CFPediatric Centre, Hannover Medical School, Germany), Matthias Griese (CF-Pediatric Centre, Ludwig Maximilian University, Munich, Germany), Frank-Michael Müller (CF-Pediatric Centre, University of Heidelberg, Germany), Hans-Georg Posselt (CF-Pediatric Centre, Johann Wolfgang Goethe-University, Frankfurt, Germany), Thomas O.F. Wagner (CF-Adult Centre, Wolfgang Goethe University Frankfurt, Germany), Tobias Welte (CF-Adult-Centre, Hannover Medical School, Germany), Matthias Wiebel (CF-Adult Centre, University of Heidelberg, Germany). Furthermore we thank Ulrich Baumann (Hannover Medical School, Germany) for conceptual work.

\section{Details of ethical approval}

The study has been approved by the ethic committees of the involved clinics. 


\begin{abstract}
Objective

Objective of this study is to assess and evaluate resource use in outpatient treatment in Germany and to compare it with remuneration.

\section{Methods}

Outpatient treatment was evaluated in seven different centres for paediatric and adult CF patients. Data was recorded during one representative month in 2006. A micro-costing approach was used to value resource use data.

\section{Results}

For outpatient treatment mean costs (excluding drugs) of $488 €$ per patient per quarter occurred. Correlation analyses identified significant cost drivers including age and co-morbidities (pancreatic insufficiency, hepatobiliary complications, lung function capacity or bacterial lung colonization). Remuneration covered only $51 \%$ of the total costs ( $252 €$ per patient/quarter).
\end{abstract}

\title{
Conclusions
}

As the human resources available to these centres today are already below the requirements set by the European consensus for standards of CF care it will be important for of a high level of patient care to reach a cost-covering remuneration scheme. 


\section{Introduction}

Cystic fibrosis (CF) is a complex lifelong chronic disease caused by genetic mutations. In most cases multiple organ systems are affected, most patients especially suffer from pancreatic insufficiency and respiratory complications. In Germany with a total population of 83 million people there are about 8,000 patients living with CF. For patients having more frequent diseases specialist out-patient care is regularly provided in Germany by privately owned practices in a non-hospital-based setting. However, CF outpatient care is predominantly provided in hospital-based special-care centres by a team of trained and experienced health care professionals. The result of this structural approach to patient care including frequent clinical examinations, monitoring, and extensive interventions is a cumulative median survival (39.7 years) comparable or superior to most western European countries and the US [1].

Motivation for this study was sparked a recent survey from the German Mukoviszidose e.V. [2] suggesting that German reimbursement schemes cover only for about $50 \%$ of the resources used for treatment within $\mathrm{CF}$ centres. In light of increasing cost pressure in the healthcare system the existence of CF centres and sufficient treatment for CF patients may be at risk in the future. Furthermore Germany could fall behind the rate of improvement in life expectancy that was observed during the last two decades.

Hence, the intention of this study is a detailed evaluation of direct costs in outpatient treatment of CF patients in Germany measured by valuing the actual consumption of resources and a comparison of these costs with the current reimbursement situation within the statutory health insurance system (SHI). Up to now there is no study with a detailed evaluation of costs of outpatient treatment in CF clinics which analyses costs from the point 
of view of the health care provider followed by a comparison with the remuneration of those services by the health care system. 


\section{Methods}

This multi centre, cross sectional, observational study was based on data from CF patients in continuous outpatient treatment in seven German paediatric and adult CF centres based at university hospitals in Hannover, Frankfurt, Heidelberg, and Munich between April and August 2006.

Different self administered questionnaires were developed to gather data from patients regarding resource use (questionnaire "Treatment Data") filled in by physicians and clinics personnel as well as other patient relevant information (questionnaire "Patient Data") filled in from patients themselves. In addition all health care professionals also had to fill out different questionnaires looking at e.g. provided services, time spent with patients as well as remuneration by the SHI (questionnaire "Personnel Data" and "Clinic Data"). All questionnaires were approved by the ethics committees of all clinics. Patient questionnaires were available for different age groups, e.g. to also include information provided by caregivers for paediatric patients (Version 1) for parents of patients from 0 to 13 years; 2) for adolescent patients from 14 to 17 , and 3) for adult patients).

Only patients giving informed consent were included in the study. Clinical patient data, resource utilisation and physician related time consumption for treatment was recorded for every patient during one representative month of treatment in the participating cystic fibrosis centres. The study protocol was not aimed at selecting patients in a lengthier time frame with respect to certain inclusion or exclusion criteria. Instead every patient that entered each study center within the time frame of one month was included in the study, taking the assumption that this month is sufficient to give us a representative mix of patients in daily routine care. Hence, all patients were included that visited the respective clinic during this time frame. 
A micro-costing approach was used to value resource use data. The assessment of provided services was based on the documentation by the doctors. The resource usage was calculated on real costs born by the CF centre. From the clinics point of view the costs of outpatient treatment especially are incurred by providing qualified personnel such as physicians, nurses, physiotherapists, psychologists etc. To assess the expenses salaries were analysed and costs per minute of work were calculated. Especially the costs for services such as talking to a patient, physical examinations and therapeutic services like physiotherapy, and giving nutrition, psychological or social advice were incorporated by assessing the individual length of these respective treatments (e.g. average time for individual patient consultations by a physician with patients in minutes multiplied with costs per minute of work for a physician from the perspective of hospital. For laboratory examinations the actual costs of providing the service in the clinic were assessed. Additional costs for overhead, buildings, equipment, multiple visits and salaries of further personal were calculated on a per-patient basis from data given by the clinics, patients and physicians. These results then were compared with the actual remuneration according to the official German Remuneration Scheme for Out-Patient Care (EBM) or specific reimbursement schemes previously negotiated with the sickness funds by the participating individual clinics. Calculation of costs for medication was not included in this publication. However, study results on costs for medication are reported in another paper [3].

In a first step the costs for every single service for every patient per day of treatment (first contact) were calculated on the basis of the treatment data provided by physicians and patients and the described valuation of costs. With that individual data the average costs per patient and age class were calculated. Thereby six age classes were built, so that there are three different subgroups of children and adolescents and three classes of adult patients. 
Patients normally visit the CF clinics once per quarter. For a complete analysis of direct costs of outpatient treatment it was important to also assess the extent of provided services for each patient on additional visits, the costs of materials used, equipment and facilities as well as administrative costs. In addition, personnel costs for additional interdisciplinary collaboration, specific training of personnel, documentation and further time consumption for additional tasks without a specific patient contact (e.g. continuous CF-specific medical education, writing statements for colleagues or sickness funds, organizing hospital visits, telephone calls etc.) were taken into account calculated on a per-patient basis. Overhead costs were calculated with $20 \%$ of the variable costs of services per patient.

In a last step, based on the data collected in this study the calculation of a potential cost covering flat charge for remuneration of outpatient treatment will be calculated. This will be based on the total observed resource use for outpatient treatment of CF patients.

To identify influencing factors (e.g. age, co-morbidities, lung function, bacterial lung colonization etc) a correlation analysis was performed (Spearman rank correlation) using SPSS® Version 15. 


\section{Results}

\section{Sociodemographic and clinical patient data}

326 patients could be included in the study. 159 of the 326 patients with an average age of 19.7 years are adolescents or children (up to 17 years of age) and 155 are male. 86 patients $(26.4 \%)$ were treated in the university hospital in Hanover, 82 patients $(25.1 \%)$ in Frankfurt, 37 patients (11.4\%) in Heidelberg and 121 patients (37.1\%) in Munich, reflecting a representative sample of about $30 \%$ of all patients treated in these clinics.

Common prevalent co-morbidities in the study population included pancreatic insufficiency (81.6\%), hepatobiliary complications $(28.2 \%)$, diabetes mellitus $(16.9 \%)$ and nasal polyps (17.8\%). Bacterial lung colonization (especially with pseudomonas aeroguinosa (59\% of the patients), burkholderia cepacia (2.8\% of the patients)) increased with age. Up to $95 \%$ of the adult patients were affected by any bacteria. Table 1 gives an overview about the clinical data of the patients.

\section{Table 1: Clinical patient data}

A comparison with data from the German patient registry [1] $(n=7,460)$ revealed no apparent differences in terms of patient characteristics. Hence, the study population might be presumed as representative of the overall CF-population in Germany. 


\section{Resource usage}

Patients undergo a continuous observation of their health state by specialised personnel of the clinics. More than $80 \%$ of the patients visited the CF clinics due to routine checkups (once per quarter), the remaining $20 \%$ because of intravenous therapies or for acute reasons. The routine check-up usually included a discussion with the doctor (96.6\%) as well as a general physical examination (94.5\%), controls of lung function $(67.8 \%)$ and oxygen saturation $\left(\mathrm{SO}_{2}\right)(61 \%)$. Furthermore microbiological (47.9\%), haematological (68.7\%), immunological (41.7\%) and biochemistry laboratory tests $(62.9 \%)$ were taken. Diagnostic services such as X-rays or ultrasound imaging were reported for less than $15 \%$.

The proportion of patients receiving therapeutic treatments such as physiotherapy $(17.2 \%)$, nutritional advice $(12.9 \%)$, patient instruction $(11.7 \%)$ or psychological/psychosocial and legal advice (each 4\%) was rather low. This can be explained with lack of qualified personnel in the clinics due to underfinancing. The European consensus [3] recommends 9.6-11.8 personnel units for inpatient and outpatient paediatric clinics and 12.4-13.6 personnel for adult clinics per 100 patients, including for both types $1.4-1.6$ physicians. In this German study sample for outpatient care a personnel of 2.36, including 0.84 physicians per 100 patients was reported. Although comparing of these figures is difficult, these figures show that in comparison to the European consensus for the treatment of CF patients an undersupply of personnel seems to be reality in German CF centres 


\section{Costs of outpatient treatment}

\section{Calculation of total costs}

Details of the incurred resource use and the distribution between cost domains can be extracted from table 2. Displayed costs due to the resources used in the clinic are adding up to mean of $488 €$ per patient per quarter in 2006 . Altogether there are more laboratory services with increasing age, caused by more microbiological diagnostic according to bacterial lung colonization.

Table 2 and Figure 1: Costs for outpatient care per patient per quarter

Overall, additional costs were substantial with $258.60 €$ per patient per quarter from the perspective of the clinics. This can be sliced down to costs for multiple visits $(32.22 €, 12.5$ $\%)$, cost for further personnel (e.g. coordination efforts, patient information etc.) (134.23 $€$, $51.9 \%)$, consumable materials (39.74 $€, 15.3 \%)$, and technical equipment, building overheads as well as administrative costs $(52.41 €, 20.3 \%)$. No correlation was found between additional costs and disease severity or age, so that for every patient those additional costs were added to the costs of the services provided on the day of treatment.

Due to the high proportion of personnel costs within the total cost, we checked the influence in a sensitivity analysis. An increase of wages by $10 \%$ led to an increase of total cost by $4.1 \%$, whereas a $20 \%$ increase led to an increase of total cost by $8.3 \%$. 


\section{Identification of cost-influencing factors}

Table 3 shows that the costs for outpatient treatment correlate with age as well as with the existence of hepatobiliary complications or the existence of bacterial lung colonization (Spearman rank correlation, $\mathrm{p}<0.010$ ). There is also a weak correlation with the comorbidities pancreatic insufficiency, diabetes mellitus and nasal polyps (Spearman rank correlation, $\mathrm{p}<0.050)$. Regarding the lung function no significant correlation could be found. Nevertheless, a classification of severity using $\% \mathrm{FEV}_{1}$ values results in a correlation coefficient of -0.125 (Spearman rank correlation, $\mathrm{p}=0.053$ ). Hence, for further analyses the variables age, pancreatic insufficiency, bacterial lung colonization as well as $\% \mathrm{FEV}_{1}$ were taken into account.

Table 3: Significant correlations of costs for outpatient treatment

Table 4: Cost analysis with regard to selected cost-influencing factors

Table 4 shows average total costs of $466 €$ for children and $509 €$ for adults per quarter. There were $9.1 \%$ (Mann Whitney U-Test, $\mathrm{p}=0.000$ ) higher total costs for adults than for children and adolescents (with pancreatic insufficiency + 9.3\% (Mann Whitney U-Test, p=0.010); with bacterial lung colonization $+11 \%$ (Mann Whitney U-Test, $\mathrm{p}=0.002)$ ).

Dividing the patients into four severity groups (patients with standard values $\% \mathrm{FEV}_{1} \geq 80$ : patients with mild disease; $60 \leq \% \mathrm{FEV}_{1}<80$ : patients with moderate disease $40 \leq \% \mathrm{FEV}_{1}<$ 60; and with severe disease $\% \mathrm{FEV}_{1}<40$ ) average costs per quarter ranged from $497 €$ for patients with standard values and $538 €$ for patients with severe restrictions (low severity: 531 


\section{Reimbursement for outpatient treatment in CF centres}

\section{Current reimbursement}

As seen costs from the point of view of the health care provider amount to an average of $488 €$ per patient per quarter. In addition, the costs for outpatient treatment are also influenced by factors such as age or co-morbidities.

In principle, all services in ambulatory care in Germany are reimbursed via the EBM (EBM Einheitlicher Bewertungsmassstab). Sickness funds each year pay a lump sum (around €500) for every insured person to the Physicians Association (KV). The KV then (by law) is responsible for the supply of sufficient services in all specialties. Based on the EBM physicians have to report all provided services to the KV. Each single service has a specific code with a value attached to it that is then paid to the physician by the KV. However, under rare circumstances where the provision of health care in a specific specialty or a specific disease is proven to be significantly underfunded or for services that are not included in the EBM the sickness funds might grant extra payments under case-specific contractual arrangements. A few participating study centers managed to apply for such an additional lump sum payment, which is also included in the present analysis.

According to different organisational setting and reimbursement schemes the remuneration for individual treatments was not homogeneous in all clinics: In four clinics remuneration for the treatment was calculated by the official German uniform value scheme for outpatient 
services. In two clinics an additional lump sum for costs of materials was paid by sickness funds. The other clinics received a fixed lump sum per patient per quarter. The total remuneration was calculated for all clinics. On average the total remuneration of services came to $252 €$. In the following figure average costs and remuneration are compared per age group:

Figure 2: Average reimbursement of clinics per patient per quarter

Comparison of the costs for resource usage and remuneration indicates that on average only about $51 \%$ of the costs per patient are reimbursed (also varying with age of the patients). The remainder is left to the clinic and thus not reimbursed at all. An alternative calculation only with official outpatient EBM-figures not including the negotiated additional flat fees of some clinics showed cost coverage of merely about $27 \%$.

These results suggest that currently specialized cystic fibrosis centres cost-covering are not operating at a cost covering basis. However, these centres are an essential part in the provision of services and therefore in most cases internally co-financed by other university units.

\section{Calculation of a remuneration covering resource usage}

As remuneration by German fee schemes will not lead to a full coverage of costs alternative reimbursement schemes should be thought of. Without distinction between age groups or other categories the calculated total cost of $488 €$ could be the value of a flat fee per patient per quarter. However, differentiated rates might be desirable. Table 5 shows the calculation of 
Table 5: Calculation of a flat fee covering resource usage

Besides the calculation of a total flat fee leading to coverage of costs in CF clinics, there are more possibilities for cost coverage through remuneration: for example the calculation of a "CF flat fee" in addition to the remuneration by German outpatient services payment schemes (EBM). In contrast to the calculation of an overall flat charge, services would only be reimbursed according to EBM if they are actually rendered. Therefore, it would be possible to cover additional costs in the CF clinics as well as that part of the services which is not covered by reimbursement according to EBM (especially laboratory services) (see table 6).

Table 6: Calculation of a „CF flat charge“" in addition to remuneration by German EBM figures

\section{Discussion}

This prospective study confirmed a previous survey and common belief among physicians that roughly $50 \%$ of the actual resource use incurred in hospital based outpatient centres in Germany is covered by the public German health insurance system (SHI). As the human resources available to these centres today are already below requirements as set by the European consensus for standards of CF care [4], patient care by hospital based outpatient centres seems to be at risk. In order to even maintain current level of CF-patient care, it will be critical for these centres to gain a cost-covering remuneration. This may be based on a flat 
charge that could be differentiated for paediatric and adult centres or according to comorbidities like pancreatic insufficiency. Furthermore a "CF flat charge" besides the standard German EBM reimbursement might be an option. The data in this study should be used to trigger and support discussions between health care providers and insurances about new costcovering reimbursement systems for the outpatient treatment of CF patients in Germany. However, even the remuneration suggested by our study will not be sufficient to achieve a level of care as mandated by the European consensus [4], which would lead to almost twofold resource uses in the clinics as reported in this study.

Former studies looking at cost evaluation for CF mostly had different approaches of evaluation, different perspectives and assessed different cost domains [5-13]. Furthermore, most of the studies were done in the 1980's and 90's or cost estimates were assessed by expert opinion left to be less valid. Moreover most of the studies were performed in single countries (USA, Netherlands, and Canada) so that national influences e.g. regarding the population structure, demographic characteristics or the healthcare system have to be considered. It should be stated that the present study focuses on the evaluation and analysis of the real costs meaning resource use incurred in outpatient treatment in CF clinics in Germany. This topic was addressed in one German study by Bauman et al. from 1996 [14]. However, they only included children and adolescents in the study. In addition, costs were calculated with prices taking the perspective of the sickness funds, not from the point of view of the clinics as health care providers. Broadening the focus to available cost of illness studies in other conditions in the German setting, future studies could help to put the figures of CF reported here into perspective to these other chronic diseases. A first assessment of evidence from different musculoskeletal conditions gives an indication that resources needed for outpatient treatment of CF patient on an individual level seems rather high, but, of course, less important from an overall budget impact standpoint [15-16]. 
The study has some limiting factors: One limitation is the fact that the calculation of costs is based on data which was stated by doctors and patients in the questionnaires. This can cause underestimation of the length and amount of treatments. Furthermore, taking the contact time with clinic personnel from a patient's observation can lead to a bias. Nevertheless this was seen as a second-best-solution as there was no possibility to measure the exact contact time on a per-patient per-service taken basis.

According to the high number of study participants and the standards by the European consensus a higher number especially of diagnostic and therapeutic treatments were expected. One reason for this could be that the clinics are understaffed. Outpatient treatment is done by a mean of 2.36 personnel, with an existing recommendation of 9.6 to 13.6 persons by the European consensus for inpatient and outpatient care. As a result services and therefore costs might be underestimated, if care regarding to accepted clinical guidelines would be provided. A calculation based on the findings comes to the conclusion that approximately $800 €$ per patient per quarter would be needed as reimbursement to cover resource use if partial for outpatient care as suggested by the European consensus would be provided. Furthermore it should be stated that the calculations in important cost domains are based on the current salary system which could lead to an underestimation of personnel costs in future reimbursement negotiations.

Looking at the documentation of reimbursement data according to EBM there might be a tendency to underestimate figures as some data could be lost during documentation or some treatments were performed, but not reimbursable. Furthermore, remuneration depends on additional reimbursement contracts of the participating clinics. 
Further research projects in this area should aim at confirming these results and widening the scope of the study to other sectors like rehabilitation. The database could be improved through new data collections in additional clinics or for a longer time frame. Moreover the existence of more detailed real cost data in the centres would be desirable for future studies.

In a first step, the evaluation of costs could be broadened to the total costs of the all health care providers (costs of outpatient as well as inpatient treatment) or from the perspective of sickness funds (i.e. also reimbursement for general practitioners or rehabilitation institutions). From the macroeconomic point of view also indirect costs due to reductions in work capacity, premature death or costs borne by caregivers like parents could be considered.

Nonetheless, international studies could shed some light on the effects of different healthcare systems and forms of organisation of CF-treatment on the costs and efficacy of treatments. 


\section{References}

1. Stern M, Sens B, Wiedemann B, Busse O, Damm G, Wenzlaff P, editors. Qualitätssicherung Mukoviszidose - Überblick über den Gesundheitszustand der Patienten in Deutschland 2007. Bad Honnef. Hippocampus Verlag; 2009.

2. German Cystic Fibrosis Patient Advacacy Group. Internal member surveys, Personal communication, Data on file, 2008.

3. Eidt-Koch D, Wagner TOF, Mittendorf T, Schulenburg JM. Outpatient medication costs of patients with cystic fibrosis in Germany. Applied Health Economics and Health Policy Decision 2010:8(02):111-118.

4. Kerem E, Conway S, Elborn S, Heijerman H. Standards of care for patients with cystic fibrosis: a European consensus. J Cyst Fibros 2005;4:7-26.

5. Krauth C, Jalilvand N, Welte T, Busse R. Cystic fibrosis - cost of illness and considerations for the economic evaluation of potential therapies. Pharmacoeconomics 2003;14:1001-24.

6. Ireys H, Anderson G, Shaffer T, Neff JM. Expenditures for care of children with chronic illnesses enrolled in Washington State Medicaid Program, fiscal year 1993. Pediatrics 1997;100:197-204.

7. Johnson JA, Connolly MA, Jacobs P, Montgomery M, Brown NE, Zuberbuhler P. Cost of care for individuals with cystic fibrosis: a regression approach to determining the impact of recombinant human DNase. Pharmacotherapy 1999;19:1159-66.

8. Lieu TA, Ray GT, Farmer G, Shay GF. The cost of medical care for patients with cystic fibrosis in a health maintenance organization. Pediatrics 1999;103:e72.

9. Pauly MV. The economics of cystic fibrosis In: Lloyd-Still JD, editor. Textbook of cystic fibrosis. Boston: John Wright PSG Inc. 1983;465-76. 
10. Robson M, Abbott J, Webb K, Dodd M, Walsworth-Bell J. A cost description of an adult cystic fibrosis unit and cost analyses of different categories of patients. Thorax 1992;47:684-9.

11. Schreyögg J, Hollmeyer H, Bluemel M, Staab D, Busse R. Hospitalisation costs of cystic fibrosis. Pharmacoeconomics 2006;10:999-1009.

12. Wildhagen MF, Verheij JB, Hilderink HBM, Kooij L, Tijmstra T, ten Kate LP, Gerritsen J, Bakker, W, Habbema, JDF. Cost of care of patients with cystic fibrosis in The Netherlands in 1990-1. Thorax 1996:51:298-301.

13. Wildhagen MF, Verheij JB, Verzijl JG et al. The nonhospital costs of care of patients with CF in the Netherlands: results of a questionnaire. Eur Resp J 1996;9:2215-9.

14. Baumann U, Stocklossa C, Greiner W. Cost of care and clinical condition in paediatric cystic fibrosis patients. J Cyst Fibros 2003;2:84-90.

15. Huscher D, Merkesdal S, Thiele $\mathrm{K}$ et al. Cost of illness in rheumatoid arthritis, ankylosing spondylitis, psoriatic arthritis and systematic lupus erythematosus in Germany. Ann Rheum Dis 2006; 65:1175-1183.

16. Ruof J, Hülsemann J L, Mittendorf T et al. Costs of rheumatoid arthritis in Germany: a micro-costing approach based on healthcare payer's data sources. Ann Rheum Dis 2003; 62:544-550. 
1

2

3

\title{
Original article
}

\section{Resource usage in outpatient care and reimbursement for cystic fibrosis in Germany}

\author{
Eidt-Koch, Daniela* PhD \\ Wagner, Thomas O.F. ** MD \\ Mittendorf, Thomas * PhD \\ Reimann, Andreas *** $\mathrm{PhD}$
}

von der Schulenburg, J.-Matthias * PhD

* Centre for Health Economics, Leibniz University of Hannover, Germany

** CF-Adult Centre, Johann Wolfgang Goethe-University, Frankfurt, Germany

*** Mukoviszidose e.V., Bonn, Germany

Key Words: Cost analysis, reimbursement, cystic fibrosis, Germany

\section{Correspondence:}

Dr. Daniela Eidt-Koch, Leibniz University Hannover, Centre for Health Economics, Koenigsworther Platz 1; D-30167 Hannover, Email: de@ivbl.uni-hannover.de; Tel : +49-511762-5518; Fax : +49-511-762-5081

Running title: Cost analysis for cystic fibrosis in Germany

\section{-1 -}




\section{Details of funding / Competing interests / Statement of independence of researchers from funders}

The study has been funded by Mukoviszidose e.V, the German CF association, Andreas Reimann is executive director and Thomas OF Wagner is board member of Mukoviszidose e.V. However, the research of the study is independent from this relationship as well as the funding.

\section{Acknowledgements}

We would like to thank Mukoviszidose e.V., the German Cystic Fibrosis Association, as well as the clinics and patients for their support and information they provided for this analysis. Especially we thank the CF Study Groups from the following clinics: Manfred Ballmann (CFPediatric Centre, Hannover Medical School, Germany), Matthias Griese (CF-Pediatric Centre, Ludwig Maximilian University, Munich, Germany), Frank-Michael Müller (CF-Pediatric Centre, University of Heidelberg, Germany), Hans-Georg Posselt (CF-Pediatric Centre, Johann Wolfgang Goethe-University, Frankfurt, Germany), Thomas O.F. Wagner (CF-Adult Centre, Wolfgang Goethe University Frankfurt, Germany), Tobias Welte (CF-Adult-Centre, Hannover Medical School, Germany), Matthias Wiebel (CF-Adult Centre, University of Heidelberg, Germany). Furthermore we thank Ulrich Baumann (Hannover Medical School, Germany) for conceptual work.

\section{Details of ethical approval}

The study has been approved by the ethic committees of the involved clinics. 


\section{Abstract}

Objective

Objective of this study is to assess and evaluate resource use in outpatient treatment in Germany and to compare it with remuneration.

Methods

Outpatient treatment was evaluated in seven different centres for paediatric and adult CF patients. Data was recorded during one representative month in 2006. A micro-costing approach was used to value resource use data.

Results

For outpatient treatment mean costs (excluding drugs) of $488 €$ per patient per quarter occurred. Correlation analyses identified significant cost drivers including age and co-morbidities (pancreatic insufficiency, hepatobiliary complications, lung function capacity or bacterial lung colonization). Remuneration covered only $51 \%$ of the total costs ( $252 €$ per patient/quarter).

\section{Conclusions}

As the human resources available to these centres today are already below the requirements set by the European consensus for standards of $\mathrm{CF}$ care it will be important for of a high level of patient care to reach a cost-covering remuneration scheme. 


\section{Introduction}

Cystic fibrosis (CF) is a complex lifelong chronic disease caused by genetic mutations. In most cases multiple organ systems are affected, most patients especially suffer from pancreatic insufficiency and respiratory complications. In Germany with a total population of 83 million people there are about 8,000 patients living with CF. For patients having more frequent diseases specialist out-patient care is regularly provided in Germany by privately owned practices in a non-hospital-based setting. However, CF outpatient care is predominantly provided in hospital-based special-care centres by a team of trained and experienced health care professionals. The result of this structural approach to patient care including frequent clinical examinations, monitoring, and extensive interventions is a cumulative median survival (39.7 years) comparable or superior to most western European countries and the US [1].

Motivation for this study was sparked a recent survey from the German Mukoviszidose e.V. [2] suggesting that German reimbursement schemes cover only for about $50 \%$ of the resources used for treatment within $\mathrm{CF}$ centres. In light of increasing cost pressure in the healthcare system the existence of CF centres and sufficient treatment for CF patients may be at risk in the future. Furthermore Germany could fall behind the rate of improvement in life expectancy that was observed during the last two decades.

Hence, the intention of this study is a detailed evaluation of direct costs in outpatient treatment of $\mathrm{CF}$ patients in Germany measured by valuing the actual consumption of resources and a comparison of these costs with the current reimbursement situation within the statutory health insurance system (SHI). Up to now there is no study with a detailed evaluation of costs of outpatient treatment in CF clinics which analyses costs from the point

\section{$-4-$}


of view of the health care provider followed by a comparison with the remuneration of those services by the health care system. 


\section{Methods}

This multi centre, cross sectional, observational study was based on data from CF patients in continuous outpatient treatment in seven German paediatric and adult CF centres based at university hospitals in Hannover, Frankfurt, Heidelberg, and Munich between April and August 2006.

Different self administered questionnaires were developed to gather data from patients regarding resource use (questionnaire "Treatment Data") filled in by physicians and clinics personnel as well as other patient relevant information (questionnaire "Patient Data") filled in from patients themselves. In addition all health care professionals also had to fill out different questionnaires looking at e.g. provided services, time spent with patients as well as remuneration by the SHI (questionnaire "Personnel Data" and "Clinic Data"). All questionnaires were approved by the ethics committees of all clinics. Patient questionnaires were available for different age groups, e.g. to also include information provided by caregivers for paediatric patients (Version 1) for parents of patients from 0 to 13 years; 2) for adolescent patients from 14 to 17 , and 3) for adult patients).

Only patients giving informed consent were included in the study. Clinical patient data, resource utilisation and physician related time consumption for treatment was recorded for every patient during one representative month of treatment in the participating cystic fibrosis centres. The study protocol was not aimed at selecting patients in a lengthier time frame with respect to certain inclusion or exclusion criteria. Instead every patient that entered each study center within the time frame of one month was included in the study, taking the assumption that this month is sufficient to give us a representative mix of patients in daily routine care. Hence, all patients were included that visited the respective clinic during this time frame.

$$
-6-
$$


A micro-costing approach was used to value resource use data. The assessment of provided services was based on the documentation by the doctors. The resource usage was calculated on real costs born by the CF centre. From the clinics point of view the costs of outpatient treatment especially are incurred by providing qualified personnel such as physicians, nurses, physiotherapists, psychologists etc. To assess the expenses salaries were analysed and costs per minute of work were calculated. Especially the costs for services such as talking to a patient, physical examinations and therapeutic services like physiotherapy, and giving nutrition, psychological or social advice were incorporated by assessing the individual length of these respective treatments (e.g. average time for individual patient consultations by a physician with patients in minutes multiplied with costs per minute of work for a physician from the perspective of hospital. For laboratory examinations the actual costs of providing the service in the clinic were assessed. Additional costs for overhead, buildings, equipment, multiple visits and salaries of further personal were calculated on a per-patient basis from data given by the clinics, patients and physicians. These results then were compared with the actual remuneration according to the official German Remuneration Scheme for Out-Patient Care (EBM) or specific reimbursement schemes previously negotiated with the sickness funds by the participating individual clinics. Calculation of costs for medication was not included in this publication. However, study results on costs for medication are reported in another paper $[3]$.

In a first step the costs for every single service for every patient per day of treatment (first contact) were calculated on the basis of the treatment data provided by physicians and patients and the described valuation of costs. With that individual data the average costs per patient and age class were calculated. Thereby six age classes were built, so that there are three different subgroups of children and adolescents and three classes of adult patients. 
Patients normally visit the CF clinics once per quarter. For a complete analysis of direct costs of outpatient treatment it was important to also assess the extent of provided services for each patient on additional visits, the costs of materials used, equipment and facilities as well as administrative costs. In addition, personnel costs for additional interdisciplinary collaboration, specific training of personnel, documentation and further time consumption for additional tasks without a specific patient contact (e.g. continuous CF-specific medical education, writing statements for colleagues or sickness funds, organizing hospital visits, telephone calls etc.) were taken into account calculated on a per-patient basis. Overhead costs were calculated with $20 \%$ of the variable costs of services per patient.

In a last step, based on the data collected in this study the calculation of a potential cost covering flat charge for remuneration of outpatient treatment will be calculated. This will be based on the total observed resource use for outpatient treatment of CF patients.

To identify influencing factors (e.g. age, co-morbidities, lung function, bacterial lung colonization etc) a correlation analysis was performed (Spearman rank correlation) using SPSS® Version 15.

$-8-$ 


\section{Results}

\section{Sociodemographic and clinical patient data}

326 patients could be included in the study. 159 of the 326 patients with an average age of 19.7 years are adolescents or children (up to 17 years of age) and 155 are male. 86 patients $(26.4 \%)$ were treated in the university hospital in Hanover, 82 patients $(25.1 \%)$ in Frankfurt, 37 patients (11.4\%) in Heidelberg and 121 patients (37.1\%) in Munich, reflecting a representative sample of about $30 \%$ of all patients treated in these clinics.

Common prevalent co-morbidities in the study population included pancreatic insufficiency $(81.6 \%)$, hepatobiliary complications $(28.2 \%)$, diabetes mellitus $(16.9 \%)$ and nasal polyps (17.8\%). Bacterial lung colonization (especially with pseudomonas aeroguinosa (59\% of the patients), burkholderia cepacia (28\% of the patients)) increased with age. Up to $95 \%$ of the adult patients were affected by any bacteria. Table 1 gives an overview about the clinical data of the patients.

\section{Table 1: Clinical patient data}

A comparison with data from the German patient registry $[1](n=7,460)$ revealed no apparent differences in terms of patient characteristics. Hence, the study population might be presumed as representative of the overall CF-population in Germany.

$-9-$ 


\section{Resource usage}

Patients undergo a continuous observation of their health state by specialised personnel of the clinics. More than $80 \%$ of the patients visited the CF clinics due to routine checkups (once per quarter), the remaining $20 \%$ because of intravenous therapies or for acute reasons. The routine check-up usually included a discussion with the doctor (96.6\%) as well as a general physical examination $(94.5 \%)$, controls of lung function $(67.8 \%)$ and oxygen saturation $\left(\mathrm{SO}_{2}\right)(61 \%)$.

Furthermore microbiological (47.9\%), haematological (68.7\%), immunological (41.7\%) and biochemistry laboratory tests $(62.9 \%)$ were taken. Diagnostic services such as $\mathrm{x}$-rays or ultrasound imaging were reported for less than $15 \%$.

The proportion of patients receiving therapeutic treatments such as physiotherapy (17.2\%), nutritional advice (12.9\%), patient instruction $(11.7 \%)$ or psychological/psychosocial and legal advice (each 4\%) was rather low. This can be explained with lack of qualified personnel in the clinics due to underfinancing. The European consensus [3] recommends 9.6-11.8 personnel units for inpatient and outpatient paediatric clinics and 12.4-13.6 personnel for adult clinics per 100 patients, including for both types 1.4-1.6 physicians. In this German study sample for outpatient care a personnel of 2.36, including 0.84 physicians per 100 patients was reported. Although comparing of these figures is difficult, these figures show that in comparison to the European consensus for the treatment of CF patients an undersupply of personnel seems to be reality in German CF centres

$-10-$ 


\section{Costs of outpatient treatment}

\section{Calculation of total costs}

Details of the incurred resource use and the distribution between cost domains can be extracted from table 2. Displayed costs due to the resources used in the clinic are adding up to mean of $488 €$ per patient per quarter in 2006. Altogether there are more laboratory services with increasing age, caused by more microbiological diagnostic according to bacterial lung colonization.

Table 2 and Figure 1: Costs for outpatient care per patient per quarter

Overall, additional costs were substantial with $258.60 €$ per patient per quarter from the perspective of the clinics. This can be sliced down to costs for multiple visits (32.22 €, 12.5 $\%$ ), cost for further personnel (e.g. coordination efforts, patient information etc.) (134.23 $€$, $51.9 \%)$, consumable materials $(39.74 €, 15.3 \%)$, and technical equipment, building overheads as well as administrative costs $(52.41 €, 20.3 \%)$. No correlation was found between additional costs and disease severity or age, so that for every patient those additional costs were added to the costs of the services provided on the day of treatment.

Due to the high proportion of personnel costs within the total cost, we checked the influence in a sensitivity analysis. An increase of wages by $10 \%$ led to an increase of total cost by $4.1 \%$, whereas a $20 \%$ increase led to an increase of total cost by $8.3 \%$. 


\section{Identification of cost-influencing factors}

Table 3 shows that the costs for outpatient treatment correlate with age as well as with the existence of hepatobiliary complications or the existence of bacterial lung colonization (Spearman rank correlation, $\mathrm{p}<0.010$ ). There is also a weak correlation with the comorbidities pancreatic insufficiency, diabetes mellitus and nasal polyps (Spearman rank correlation, $\mathrm{p}<0.050)$. Regarding the lung function no significant correlation could be found. Nevertheless, a classification of severity using $\% \mathrm{FEV}_{1}$ values results in a correlation coefficient of -0.125 (Spearman rank correlation, $\mathrm{p}=0.053$ ). Hence, for further analyses the variables age, pancreatic insufficiency, bacterial lung colonization as well as $\% \mathrm{FEV}_{1}$ were taken into account.

Table 3: Significant correlations of costs for outpatient treatment

Table 4: Cost analysis with regard to selected cost-influencing factors

Table 4 shows average total costs of $466 €$ for children and $509 €$ for adults per quarter. There were $9.1 \%$ (Mann Whitney U-Test, $\mathrm{p}=0.000$ ) higher total costs for adults than for children and adolescents (with pancreatic insufficiency $+9.3 \%$ (Mann Whitney U-Test, $\mathrm{p}=0.010$ ); with bacterial lung colonization $+11 \%$ (Mann Whitney U-Test, $\mathrm{p}=0.002)$ ).

Dividing the patients into four severity groups (patients with standard values $\% \mathrm{FEV}_{1} \geq 80$ : patients with mild disease; $60 \leq \% \mathrm{FEV}_{1}<80$ : patients with moderate disease $40 \leq \% \mathrm{FEV}_{1}<$ 60; and with severe disease $\% \mathrm{FEV}_{1}<40$ ) average costs per quarter ranged from $497 €$ for patients with standard values and $538 €$ for patients with severe restrictions (low severity: 531

$-12-$ 
$€$; medium severity: $499 €$ ). These costs do not include medication which had been assessed during the overall study, but is not subject to this publication.

\section{Reimbursement for outpatient treatment in CF centres}

\section{Current reimbursement}

As seen costs from the point of view of the health care provider amount to an average of $488 €$ per patient per quarter. In addition, the costs for outpatient treatment are also influenced by factors such as age or co-morbidities.

In principle, all services in ambulatory care in Germany are reimbursed via the EBM (EBM Einheitlicher Bewertungsmassstab). Sickness funds each year pay a lump sum (around €500) for every insured person to the Physicians Association (KV). The KV then (by law) is responsible for the supply of sufficient services in all specialties. Based on the EBM physicians have to report all provided services to the KV. Each single service has a specific code with a value attached to it that is then paid to the physician by the KV. However, under rare circumstances where the provision of health care in a specific specialty or a specific disease is proven to be significantly underfunded or for services that are not included in the EBM the sickness funds might grant extra payments under case-specific contractual arrangements. A few participating study centers managed to apply for such an additional lump sum payment, which is also included in the present analysis.

According to different organisational setting and reimbursement schemes the remuneration for individual treatments was not homogeneous in all clinics: In four clinics remuneration for the treatment was calculated by the official German uniform value scheme for outpatient $-13-$ 
services. In two clinics an additional lump sum for costs of materials was paid by sickness funds. The other clinics received a fixed lump sum per patient per quarter. The total remuneration was calculated for all clinics. On average the total remuneration of services came to $252 €$. In the following figure average costs and remuneration are compared per age group:

Figure 2: Average reimbursement of clinics per patient per quarter

Comparison of the costs for resource usage and remuneration indicates that on average only about $51 \%$ of the costs per patient are reimbursed (also varying with age of the patients). The remainder is left to the clinic and thus not reimbursed at all. An alternative calculation only with official outpatient EBM-figures not including the negotiated additional flat fees of some clinics showed cost coverage of merely about $27 \%$.

These results suggest that currently specialized cystic fibrosis centres cost-covering are not operating at a cost covering basis. However, these centres are an essential part in the provision of services and therefore in most cases internally co-financed by other university units.

\section{Calculation of a remuneration covering resource usage}

As remuneration by German fee schemes will not lead to a full coverage of costs alternative reimbursement schemes should be thought of. Without distinction between age groups or other categories the calculated total cost of $488 €$ could be the value of a flat fee per patient per quarter. However, differentiated rates might be desirable. Table 5 shows the calculation of -14 - 
a cost-covering flat charge by distinguishing between paediatric and adult clinics as well as cost-influencing factors like pancreatic insufficiency or bacterial lung colonization.

\section{Table 5: Calculation of a flat fee covering resource usage}

Besides the calculation of a total flat fee leading to coverage of costs in CF clinics, there are more possibilities for cost coverage through remuneration: for example the calculation of a "CF flat fee" in addition to the remuneration by German outpatient services payment schemes (EBM). In contrast to the calculation of an overall flat charge, services would only be reimbursed according to EBM if they are actually rendered. Therefore, it would be possible to cover additional costs in the CF clinics as well as that part of the services which is not covered by reimbursement according to EBM (especially laboratory services) (see table 6).

\section{Table 6: Calculation of a „CF flat charge“ in addition to remuneration by German EBM figures}

\section{Discussion}

This prospective study confirmed a previous survey and common belief among physicians that roughly $50 \%$ of the actual resource use incurred in hospital based outpatient centres in resources available to these centres today are already below requirements as set by the European consensus for standards of CF care [4], patient care by hospital based outpatient centres seems to be at risk. In order to even maintain current level of CF-patient care, it will be critical for these centres to gain a cost-covering remuneration. This may be based on a flat 
charge that could be differentiated for paediatric and adult centres or according to comorbidities like pancreatic insufficiency. Furthermore a "CF flat charge" besides the standard German EBM reimbursement might be an option. The data in this study should be used to trigger and support discussions between health care providers and insurances about new costcovering reimbursement systems for the outpatient treatment of CF patients in Germany. However, even the remuneration suggested by our study will not be sufficient to achieve a level of care as mandated by the European consensus [4], which would lead to almost twofold resource uses in the clinics as reported in this study.

Former studies looking at cost evaluation for CF mostly had different approaches of evaluation, different perspectives and assessed different cost domains [5-13]. Furthermore, most of the studies were done in the 1980's and 90's or cost estimates were assessed by expert opinion left to be less valid. Moreover most of the studies were performed in single countries (USA, Netherlands, and Canada) so that national influences e.g. regarding the population structure, demographic characteristics or the healthcare system have to be considered. It should be stated that the present study focuses on the evaluation and analysis of the real costs meaning resource use incurred in outpatient treatment in CF clinics in Germany. This topic was addressed in one German study by Bauman et al. from 1996 [14]. However, they only included children and adolescents in the study. In addition, costs were calculated with prices taking the perspective of the sickness funds, not from the point of view of the clinics as health care providers. Broadening the focus to available cost of illness studies in other conditions in the German setting, future studies could help to put the figures of CF reported here into perspective to these other chronic diseases. A first assessment of evidence from different musculoskeletal conditions gives an indication that resources needed for outpatient treatment of CF patient on an individual level seems rather high, but, of course, less important from an overall budget impact standpoint [15-16].

$$
-16-
$$


According to the high number of study participants and the standards by the European consensus a higher number especially of diagnostic and therapeutic treatments were expected. One reason for this could be that the clinics are understaffed. Outpatient treatment is done by a mean of 2.36 personnel, with an existing recommendation of 9.6 to 13.6 persons by the European consensus for inpatient and outpatient care. As a result services and therefore costs might be underestimated, if care regarding to accepted clinical guidelines would be provided. A calculation based on the findings comes to the conclusion that approximately $800 €$ per patient per quarter would be needed as reimbursement to cover resource use if partial for outpatient care as suggested by the European consensus would be provided. Furthermore it should be stated that the calculations in important cost domains are based on the current salary system which could lead to an underestimation of personnel costs in future reimbursement negotiations.

Looking at the documentation of reimbursement data according to EBM there might be a tendency to underestimate figures as some data could be lost during documentation or some treatments were performed, but not reimbursable. Furthermore, remuneration depends on additional reimbursement contracts of the participating clinics.

\section{$-17-$}


Further research projects in this area should aim at confirming these results and widening the scope of the study to other sectors like rehabilitation. The database could be improved through new data collections in additional clinics or for a longer time frame. Moreover the existence of more detailed real cost data in the centres would be desirable for future studies.

In a first step, the evaluation of costs could be broadened to the total costs of the all health care providers (costs of outpatient as well as inpatient treatment) or from the perspective of sickness funds (i.e. also reimbursement for general practitioners or rehabilitation institutions). From the macroeconomic point of view also indirect costs due to reductions in work capacity, premature death or costs borne by caregivers like parents could be considered.

Nonetheless, international studies could shed some light on the effects of different healthcare

Deleted: scatter systems and forms of organisation of CF-treatment on the costs and efficacy of treatments.

Formatted: English (U.S.) 


\section{References}

1. Stern M, Sens B, Wiedemann B, Busse O, Damm G, Wenzlaff P, editors. Qualitätssicherung Mukoviszidose - Überblick über den Gesundheitszustand der Patienten in Deutschland 2007. Bad Honnef. Hippocampus Verlag; 2009.

2. German Cystic Fibrosis Patient Advacacy Group. Internal member surveys, Personal communication, Data on file, 2008.

3. Eidt-Koch D, Wagner TOF, Mittendorf T, Schulenburg JM. Outpatient medication costs of patients with cystic fibrosis in Germany. Applied Health Economics and Health Policy Decision 2010:8(02):111-118.

4. Kerem E, Conway S, Elborn S, Heijerman H. Standards of care for patients with cystic fibrosis: a European consensus. J Cyst Fibros 2005;4:7-26.

5. Krauth C, Jalilvand N, Welte T, Busse R. Cystic fibrosis - cost of illness and considerations for the economic evaluation of potential therapies. Pharmacoeconomics 2003;14:1001-24.

6. Ireys H, Anderson G, Shaffer T, Neff JM. Expenditures for care of children with chronic illnesses enrolled in Washington State Medicaid Program, fiscal year 1993. Pediatrics 1997;100:197-204.

7. Johnson JA, Connolly MA, Jacobs P, Montgomery M, Brown NE, Zuberbuhler P. Cost of care for individuals with cystic fibrosis: a regression approach to determining the impact of recombinant human DNase. Pharmacotherapy 1999;19:1159-66.

8. Lieu TA, Ray GT, Farmer G, Shay GF. The cost of medical care for patients with cystic fibrosis in a health maintenance organization. Pediatrics 1999;103:e72.

9. Pauly MV. The economics of cystic fibrosis In: Lloyd-Still JD, editor. Textbook of cystic fibrosis. Boston: John Wright PSG Inc. 1983;465-76. 
10. Robson M, Abbott J, Webb K, Dodd M, Walsworth-Bell J. A cost description of an adult cystic fibrosis unit and cost analyses of different categories of patients. Thorax 1992;47:684-9.

11. Schreyögg J, Hollmeyer H, Bluemel M, Staab D, Busse R. Hospitalisation costs of cystic fibrosis. Pharmacoeconomics 2006;10:999-1009.

12. Wildhagen MF, Verheij JB, Hilderink HBM, Kooij L, Tijmstra T, ten Kate LP, Gerritsen J, Bakker, W, Habbema, JDF. Cost of care of patients with cystic fibrosis in The Netherlands in 1990-1. Thorax 1996:51:298-301.

13. Wildhagen MF, Verheij JB, Verzijl JG et al. The nonhospital costs of care of patients with CF in the Netherlands: results of a questionnaire. Eur Resp J 1996;9:2215-9.

14. Baumann U, Stocklossa C, Greiner W. Cost of care and clinical condition in paediatric cystic fibrosis patients. J Cyst Fibros 2003;2:84-90.

15. Huscher D, Merkesdal S, Thiele $\mathrm{K}$ et al. Cost of illness in rheumatoid arthritis, ankylosing spondylitis, psoriatic arthritis and systematic lupus erythematosus in Germany. Ann Rheum Dis 2006; 65:1175-1183.

16. Ruof J, Hülsemann J L, Mittendorf T et al. Costs of rheumatoid arthritis in Germany: a micro-costing approach based on healthcare payer's data sources. Ann Rheum Dis 2003; 62:544-550.

-20 - 
Table 1: Clinical patient data

\begin{tabular}{||l|c|c|c|c|c|c|}
\hline & \multicolumn{2}{|c|}{$\begin{array}{c}\text { Children } \\
(0 \text { to } 17 \text { years) }\end{array}$} & \multicolumn{2}{|c|}{$\begin{array}{c}\text { Adults (18 years } \\
\text { and older) }\end{array}$} & \multicolumn{2}{|c|}{ Total } \\
\hline & $\mathrm{n}$ & $\%$ & $\mathrm{n}$ & $\%$ & $\mathrm{n}$ & $\%$ \\
\hline \% vital capacity (mean) & 105 & $93.95 \%$ & 140 & $74.85 \%$ & 245 & $83.03 \%$ \\
\hline$\% \mathrm{FEV}_{1}$ (mean) & 104 & $93.88 \%$ & 138 & $52.66 \%$ & 242 & $70.37 \%$ \\
\hline$\% \mathrm{MEF}_{25}$ (mean) & 105 & $64.28 \%$ & 115 & $23.84 \%$ & 220 & $43.14 \%$ \\
\hline $\begin{array}{l}\text { Lung bacteria (pseudomonas } \\
\text { aeroguinosa, burkholderia cepacia etc) }\end{array}$ & 96 & $64.86 \%$ & 153 & $95.03 \%$ & 249 & $80.58 \%$ \\
\hline Pancreatic insufficiency & 127 & $79.87 \%$ & 139 & $83.23 \%$ & 266 & $81.60 \%$ \\
\hline Hepatobiliary complications & 37 & $23.27 \%$ & 55 & $32.93 \%$ & 92 & $28.22 \%$ \\
\hline Nasal polyp & 14 & $8.81 \%$ & 44 & $26.35 \%$ & 58 & $17.79 \%$ \\
\hline Diabetes mellitus & 3 & $1.89 \%$ & 52 & $31.14 \%$ & 55 & $16.87 \%$ \\
\hline ABPA & 10 & $6.29 \%$ & 29 & $17.37 \%$ & 39 & $11.96 \%$ \\
\hline Distal intestinal obstruction & 7 & $4.40 \%$ & 22 & $13.17 \%$ & 29 & $8.90 \%$ \\
\hline Pneumothorax & 1 & $0.63 \%$ & 13 & $7.78 \%$ & 14 & $4.29 \%$ \\
\hline Massive haemoptysis & 0 & $0.00 \%$ & 12 & $7.19 \%$ & 12 & $3.68 \%$ \\
\hline Tuberculosis & 0 & $0.00 \%$ & 1 & $0.60 \%$ & 1 & $0.31 \%$ \\
\hline $\begin{array}{l}\text { Isolation obligation for patient } \\
\text { (segregation required due to infection } \\
\text { with lung bacteria) }\end{array}$ & 6 & $3.77 \%$ & 12 & $7.19 \%$ & 18 & $5.52 \%$ \\
\hline $\begin{array}{l}\text { Patient waitlisted for lung } \\
\text { transplantation }\end{array}$ & 0 & $0.00 \%$ & 7 & $4.19 \%$ & 7 & $2.15 \%$ \\
\hline
\end{tabular}

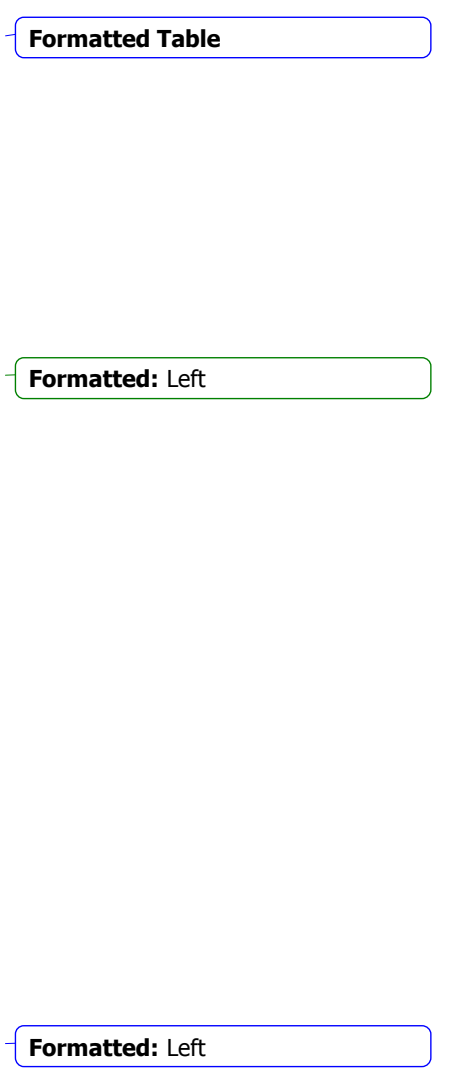


Table 1: Clinical patient data

\begin{tabular}{|l|c|c|c|c|c|c|}
\hline & \multicolumn{2}{|c|}{$\begin{array}{c}\text { Children } \\
\text { (0 to 17 years) }\end{array}$} & $\begin{array}{c}\text { Adults (18 years } \\
\text { and older) }\end{array}$ & \multicolumn{2}{c|}{ Total } \\
\hline & $\mathrm{n}$ & $\%$ & $\mathrm{n}$ & $\%$ & $\mathrm{n}$ & $\%$ \\
\hline$\%$ vital capacity (mean) & 105 & $93.95 \%$ & 140 & $74.85 \%$ & 245 & $83.03 \%$ \\
\hline$\% \mathrm{FEV}_{1}$ (mean) & 104 & $93.88 \%$ & 138 & $52.66 \%$ & 242 & $70.37 \%$ \\
\hline$\% \mathrm{MEF}_{25}$ (mean) & 105 & $64.28 \%$ & 115 & $23.84 \%$ & 220 & $43.14 \%$ \\
\hline $\begin{array}{l}\text { Lung bacteria (pseudomonas } \\
\text { aeroguinosa, burkholderia cepacia etc) }\end{array}$ & 96 & $64.86 \%$ & 153 & $95.03 \%$ & 249 & $80.58 \%$ \\
\hline Pancreatic insufficiency & 127 & $79.87 \%$ & 139 & $83.23 \%$ & 266 & $81.60 \%$ \\
\hline Hepatobiliary complications & 37 & $23.27 \%$ & 55 & $32.93 \%$ & 92 & $28.22 \%$ \\
\hline Nasal polyp & 14 & $8.81 \%$ & 44 & $26.35 \%$ & 58 & $17.79 \%$ \\
\hline Diabetes mellitus & 3 & $1.89 \%$ & 52 & $31.14 \%$ & 55 & $16.87 \%$ \\
\hline ABPA & 10 & $6.29 \%$ & 29 & $17.37 \%$ & 39 & $11.96 \%$ \\
\hline Distal intestinal obstruction & 7 & $4.40 \%$ & 22 & $13.17 \%$ & 29 & $8.90 \%$ \\
\hline Pneumothorax & 1 & $0.63 \%$ & 13 & $7.78 \%$ & 14 & $4.29 \%$ \\
\hline Massive haemoptysis & 0 & $0.00 \%$ & 12 & $7.19 \%$ & 12 & $3.68 \%$ \\
\hline Tuberculosis & 0 & $0.00 \%$ & 1 & $0.60 \%$ & 1 & $0.31 \%$ \\
\hline $\begin{array}{l}\text { Isolation obligation for patient } \\
\text { (segregation required due to infection } \\
\text { with lung bacteria) }\end{array}$ & 6 & $3.77 \%$ & 12 & $7.19 \%$ & 18 & $5.52 \%$ \\
\hline $\begin{array}{l}\text { Patient waitlisted for lung } \\
\text { transplantation }\end{array}$ & 0 & $0.00 \%$ & 7 & $4.19 \%$ & 7 & $2.15 \%$ \\
\hline
\end{tabular}


Table 2: Costs for outpatient care per patient and quarter

\begin{tabular}{|c|c|c|c|c|c|c|c|c|}
\hline & \multicolumn{3}{|c|}{ Children and adolescents } & \multicolumn{3}{|c|}{ Adults } & \multirow[b]{2}{*}{$\begin{array}{c}\text { Mean } \\
\text { (all patients) } \\
(n=326)\end{array}$} & \\
\hline & $\begin{array}{c}0-7 \\
\text { years } \\
(n=62)\end{array}$ & $\begin{array}{l}8-13 \\
\text { years } \\
(n=56)\end{array}$ & $\begin{array}{l}14-17 \\
\text { years } \\
(n=41)\end{array}$ & $\begin{array}{c}18-24 \\
\text { years } \\
(n=62)\end{array}$ & $\begin{array}{c}25-34 \\
\text { years } \\
(n=65)\end{array}$ & $\begin{array}{l}35 \text { years } \\
\text { and older } \\
(n=40)\end{array}$ & & \\
\hline $\begin{array}{l}\text { Routine medical } \\
\text { examinations }\end{array}$ & $57.16 €$ & $78.10 €$ & $75.14 €$ & $74.27 €$ & $68.00 €$ & $68.80 €$ & $69.86 €(14.3 \%)$ & \\
\hline $\begin{array}{l}\text { Laboratory }_{z} \ldots-- \\
\text { investigations }\end{array}$ & $71.77 €$ & $112.97 €$ & $147.50 €$ & $15 \underline{5} .79 €$ & $-161.60 €$ & $152.55 \underline{€}$ & $132.17 €(27.1 \%)$ & Deleted: examinations \\
\hline $\begin{array}{l}\text { Diagnostic } \\
\text { services }\end{array}$ & $5.29 €$ & $7.35 €$ & $5.33 €$ & $12.86 €$ & $7.50 €$ & $7.05 €$ & $7.75 €(1.6 \%)$ & \\
\hline $\begin{array}{l}\text { Physiotherapy, } \\
\text { dietician etc }\end{array}$ & $30.85 €$ & $20.61 €$ & $19.74 €$ & $6.77 €$ & $3.91 €$ & $2.54 €$ & $14.27 €(2.9 \%)$ & \\
\hline Other treatment & $2.21 €$ & $2.53 €$ & $3.58 €$ & $9.39 €$ & $9.68 €$ & $9.19 €$ & $5.78 €(1.2 \%)$ & \\
\hline Additional costs & $258.60 €$ & $258.60 €$ & $258.60 €$ & $258.60 €$ & $258.60 €$ & $258.60 €$ & $258.60 €(52.9 \%)$ & \\
\hline Total costs & $425.88 €$ & $480.16 €$ & $509.89 €$ & $517.68 €$ & $509.29 €$ & $495.73 €$ & $488.43 €(100,0 \%)$ & \\
\hline
\end{tabular}


Table 2: Costs for outpatient care per patient and quarter

\begin{tabular}{|l|c|c|c|c|c|c|c|}
\hline \multirow{2}{*}{} & \multicolumn{2}{|c|}{ Children and adolescents } & \multicolumn{3}{c|}{ Adults } & \\
\cline { 2 - 7 } & $\begin{array}{c}0-7 \\
\text { years } \\
(\mathrm{n}=62)\end{array}$ & $\begin{array}{c}8-13 \\
\text { years } \\
(\mathrm{n}=56)\end{array}$ & $\begin{array}{c}14-17 \\
\text { years } \\
(\mathrm{n}=41)\end{array}$ & $\begin{array}{c}18-24 \\
\text { years } \\
(\mathrm{n}=62)\end{array}$ & $\begin{array}{c}25-34 \\
\text { years } \\
(\mathrm{n}=65)\end{array}$ & $\begin{array}{c}35 \text { years } \\
\text { and older } \\
(\mathrm{n}=40)\end{array}$ & $\begin{array}{c}\text { Mean } \\
\text { (all patients) } \\
(\mathrm{n}=326)\end{array}$ \\
\hline $\begin{array}{l}\text { Routine medical } \\
\text { examinations }\end{array}$ & $57.16 €$ & $78.10 €$ & $75.14 €$ & $74.27 €$ & $68.00 €$ & $68.80 €$ & $69.86 €(14.3 \%)$ \\
\hline $\begin{array}{l}\text { Laboratory } \\
\text { investigations }\end{array}$ & $71.77 €$ & $112.97 €$ & $147.50 €$ & $155.79 €$ & $161.60 €$ & $152.55 €$ & $132.17 €(27.1 \%)$ \\
\hline $\begin{array}{l}\text { Diagnostic } \\
\text { services }\end{array}$ & $5.29 €$ & $7.35 €$ & $5.33 €$ & $12.86 €$ & $7.50 €$ & $7.05 €$ & $7.75 €(1.6 \%)$ \\
\hline $\begin{array}{l}\text { Physiotherapy, } \\
\text { dietician etc }\end{array}$ & $30.85 €$ & $20.61 €$ & $19.74 €$ & $6.77 €$ & $3.91 €$ & $2.54 €$ & $14.27 €(2.9 \%)$ \\
\hline Other treatment & $2.21 €$ & $2.53 €$ & $3.58 €$ & $9.39 €$ & $9.68 €$ & $9.19 €$ & $5.78 €(1.2 \%)$ \\
\hline Additional costs & $258.60 €$ & $258.60 €$ & $258.60 €$ & $258.60 €$ & $258.60 €$ & $258.60 €$ & $258.60 €(52.9 \%)$ \\
\hline Total costs & $425.88 €$ & $480.16 €$ & $509.89 €$ & $517.68 €$ & $509.29 €$ & $495.73 €$ & $488.43 €(100,0 \%)$ \\
\hline
\end{tabular}

